\title{
Assessment Schemes for Sustainability Design through BIM: Lessons Learnt
}

\author{
Syahrul Nizam Kamaruzzaman ${ }^{1}$, Hafez Salleh², Eric Choen Weng Lou ${ }^{3}$, Rodger Edwards ${ }^{4}$, and Phui Fung Wong ${ }^{5, a}$ \\ 1, 2, 5 Faculty of Built Environment, University of Malaya, 50603 Kuala Lumpur \\ ${ }^{3,4}$ School of Mechanical, Aerospace and Civil Engineering, The University of Manchester, Manchester M13 9PL, United Kingdom
}

\begin{abstract}
There is increasing demand on sustainability-led design to reduce negative impacts brought by construction development. The capability of Building Information Modeling (BIM) to achieve sustainability is widely acknowledged. Various sustainability analysis and calculation can be performed at early stages to help the designers in decision making. However, the level of implementation is still not popular in the construction industry. Many of the industry players are still rely on traditional 2D method for designing and analysis. Hence, this study aims to demonstrate a proof concept of using BIM for sustainability design. The first phase of this study conducted a critical review of existing assessment schemes: BREEAM, LEED, SBTool, CASBEE, BEAM Plus, Green Star, Green Mark and GBI, to develop a set of main criteria to be considered for sustainability design. The findings revealed that fourteen criteria are considered, which are management, sustainable site, transport, indoor environmental quality, energy, waste, water, material, pollution, innovation, economics, social, culture and quality of services. It was found that most of the existing schemes emphasized on environmental aspect as compared to economics, social and culture except SBTool. The next phase of this study will conduct a case study to demonstrate sustainability design through BIM by using the criteria developed from the first phase.
\end{abstract}

\section{Introduction}

The concern about global warming, greenhouse effects and pollution is increasing. There is a growing evidence of global warming and climate change which increase the necessity for immediate action to avoid potentially serious consequences for future generations [1]. Malaysia is facing an increasing trend of per capita carbon dioxide emission and energy consumption [2]. Therefore, the Malaysian government has set a voluntary target to reduce $40 \%$ of carbon emission [3]. It is noted that building is one of the highest contributions to global warming and greenhouse effect. In the UK, buildings consume near to $50 \%$ of carbon dioxide emission [4]. While in the US, buildings account for close to $50 \%$ of all the annual energy used and contributes to $40 \%$ of the global carbon emissions [5]. The environmental impact brought by the construction of buildings has attracted many professionals in the industry to consider sustainable design for their building designs. Biswas et al. [6] highlighted the demand for sustainable buildings with minimal impacts to the environment are increasing. Autodesk [7] also highlighted that a growing field within sustainable building design has emerged as building growth intersects with environmental concerns and the rising cost of energy. Therefore, the sustainability of design has becomes a critical concern in the construction

\footnotetext{
${ }^{\mathrm{a}}$ Corresponding author: wong_pf@um.edu.my
}

industry for designing, constructing and operating facilities in such a manner so as to minimize the environmental impact.

To achieve sustainable design, better monitoring building performance at the beginning stage with significant amount of accurate information is required [8]. It is noteworthy that decisions regarding sustainability of designs have to be made at the early design stages [5]. Traditional building design methods such as conventional CAD do not contain sufficient amount of information at the beginning stages to support early decision making. However, building information modeling (BIM) application allows decisions to be made at the early stages of design with rich information contained in a single coordinated model. Hence, various types of sustainability and performance analysis can be performed throughout the design process in order to improve the building performance. By incorporating BIM technology into sustainable design, it has the potential to change the traditional design practice and produce a greener building with better performance $[9,10]$. Various literature sources have provided evidence that BIM application can improve building performance to achieve sustainable design $[9,11,12]$.

The combination of sustainable design and BIM technology has the potential to improve traditional design 
practice which in turn produces a sustainable way of design. However, the use of BIM tools for sustainability assessment is still lacking [11]. Hence, this study is intended to demonstrate a sustainable design through BIM to show a proof of concept of sustainability benefits by application of BIM. This study is divided into two stages. Firstly, a critical review of assessment schemes is conducted. It seeks to review the globally prevalent environmental assessment schemes in order to find out the similarities and differences in assessing main criteria which in turn establish a list of sustainable criteria for sustainable design though BIM. Second phase of this study will integrate BIM object to demonstrate sustainable design by referring to the assessment criteria that developed from the first phase. By doing this, it can provide a comprehensive assessment criteria for government and assessment scheme developer to develop a complete scheme for sustainable design and modelling. Moreover, it can gain understandings among the architects, designers and engineers of the real case benefits of using BIM for sustainable design. This is an on-going research and the first phase of this research will report in this paper.

\section{Sustainable Design through BIM}

Sustainable designs can be achieved by carrying out various building analysis and optimization of the design to enhance building performance. In order to perform various analyzes, consistent and reliable information should be made available at the early design stages. The required data information for various analyzes including relevant data about the external environment, the shape and configuration of the building, equipment loads, lighting mechanical systems and ventilation [8]. Unfortunately, such data is often not available at the early design stages. As a result, energy and performance analysis are normally performed at the later stages which is after the architectural design stage and construction documents have been produced, thus reducing the chance for early modifications that could enhance building performance [9-11]. Moreover, to perform these analyses on a conventional way requires human interpretation which is time consuming, tedious and costly. Therefore, a tool that can support early decision making and contain sufficient amount of information is needed. Jrade and Jalaei [13] accentuated that there is a need for construction industry to adopt new technologies for building design with the purpose of reducing impacts on the environment.

BIM is an innovative way to achieve sustainable designs by reducing the energy consumption and carbon emission which ultimately delivers greener buildings. It is an approach to building design, construction and management with the use of a digital coordinated database that store a wealth of information throughout the lifecycle of the buildings. Hence, it is a rich repository that stores multi-disciplinary information in a single virtual building representation throughout the lifecycle of the buildings [5]. It allows multi-disciplinary information (structural, mechanical, electrical, plumbing and lighting) stored in a single model that allows building analysis to be performed quickly and accurately at the beginning stage. Designers are able to incorporate greener design, provide various design alternatives for sustainability and make better early decisions in order to improve building performance. BIM facilitates a complex analysis and calculation that was previously too tedious or laborious to be performed traditionally.

Krygiel and Nies [14] indicated that BIM application can achieve several aspects of sustainable designs which traditionally cannot be produced by using traditional 2D tools such as building orientation (which can reduce project cost), building massing (to analyse building form and optimise building envelope), day lighting analysis, energy modeling, water harvesting (reduce water consumption), sustainable materials (reduce virgin materials consumption), site and logistics management (reduce waste). Various sustainability analyses, assessments, evaluations and calculations can be performed to enhance air quality, thermal comfort and ultimately improve the overall energy usage by linking the building model to energy analysis tools [9-10]. Jrade and Jalaei [13] also explained that BIM supports experimental analysis of structure, environmental controls, construction method, use of new materials, or systems. Thus, BIM application provides an opportunity for industry professionals to realize the numerous benefits associated with sustainable analysis and design throughout the project.

\section{Sustainable Scheme in various regions}

Many countries have developed their own assessment schemes. Each region has its own geographical and cultural characteristics. Therefore, there are many assessment schemes developed for a specific site and local purposes. It is necessary to develop a comprehensive list of criteria by reviewing existing schemes as it is the standard for sustainable design in various regions. By gaining understanding of the criteria used, it can assist this study in demonstrating sustainable design through BIM by using the main criteria.

BREEAM (Building Research Establishment Environmental Assessment Method) is known as the first building environmental assessment scheme developed in the early 1990s. There has been a rise in the number of assessment schemes that promote sustainable building developments. Among widely known are LEED (Leadership in Energy and Environment) in US, SBTool (Sustainable Building Tool) in Canada, CASBEE (Comprehensive Assessment System for Building Environmental Efficiency) in Japan, BEAM Plus (Building Environmental Assessment Method) in Hong Kong, Green Star in Australia and Green Mark in Singapore. In Malaysia context, GBI (Green Building Index) is the assessment scheme widely adopted for building assessment.

In early 1990s, BRE Ltd (Building Research Establishment Limited) developed BREEAM to evaluate the new and existing building performance. The 
assessment scheme also include for refurbishment purpose and neighbourhood development. The development of BREEAM has a profound impact on almost all of the assessment schemes. It has been used as a template and reference model for the creation of Green Star assessment tool in Australia and BEAM-PLUS in Hong Kong [15]. Another prevalent schemes is LEED which developed by the US Green Building Council (USGBC). The assessment of LEED can be used for new, existing, renovation, interior design, homes and neighbourhood development. Meanwhile, LEED is the most widely recognized assessment scheme as it has been used to carry out in 41 countries [16].

SBTool was developed by the International Initiatives for a Sustainable Built Environment (iiSBE) and widely considered as the most comprehensive of all environmental assessment method [12]. It has been widely adapted by different countries located in Europe, Africa, Canada and the far east of Asia. Its flexibility allows the scheme to be adjusted to suit local conditions of each region and also site variations [17] which make it becomes very popular. The development of CASBEE scheme was an effort of Japan Green Building Council (JaGBC)/ Japan Sustainable Building Consortium (JSBC) and their subcommittees [16]. CASBEE was applied for pre-design, new construction, existing building and renovation building that correspond to the building life cycle. BEAM Plus is a voluntary scheme first launched in 1996 (formerly known as HK-BEAM). It was based largely on the BREEAM assessment scheme but modified for Hong Kong's densely populated infrastructure. It applied to new and existing buildings and covered a wide range of issues related to impacts of buildings on the environment in terms of global, local and indoor scales [16].

In 2003, Green Star assessment scheme was developed by a non-government organisation, the Green Building Council of Australia (GBCA). It is a comprehensive, national, voluntary environmental assessment scheme and has been adopted by other regions such as New Zealand and South Africa. In Singapore, Green Mark was introduced by Building and Construction Authority (BCA) in 2005. It aims to evaluate buildings for environmental impact and performance, and promote sustainable design, construction and operational practices throughout the City-State Republic of Singapore [17]. In 2001, the Malaysian Institute of Architects (PAM) and the Association of Consulting Engineers Malaysia (ACEM) developed GBI. It is developed based on Malaysian tropical climate, environmental and developmental context, cultural and social needs [17]. GBI is applicable to new and existing residential and commercial buildings in Malaysia.

\section{Findings and Discussion}

After holistic reviewing, among the eight schemes, assessment criteria can be divided into fourteen criteria: management, sustainable site, transport, indoor environmental quality (IEQ), water, waste, material, energy, pollution and innovation, economic, social, cultural and quality of service as illustrated in Figure 1. The detail results are tabulated in Table 1.

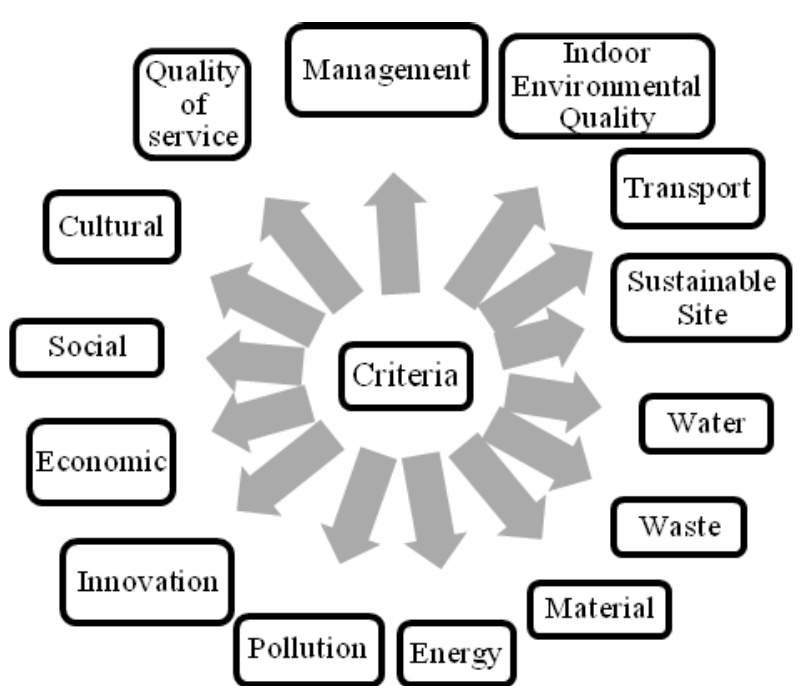

Figure 1. Main Criteria of Assessment Scheme

Table 1 showed that all assessment schemes evaluated management criteria in their assessment scheme. Management criteria deals with how buildings can be sufficiently plan, design, construct, operated and maintained throughout the building life cycle [18]. Sustainable site evaluation focused on site location which the building is to be built. It generally assesses Greenfield and Brownfield site to avoid development in inappropriate site and also reduce the environmental impact from the building. Majority of the assessment schemes assesses this criterion except Green Mark and GBI. From the Table 1, it is apparent that all of the assessment schemes evaluated transport criteria. The aim of this criterion is to deliver a good level of communication, through east access to public facilities and services and adequate provision for pedestrians, cyclists and drivers [19]. The adequacy of public transport and local amenities is essential in order to reduce congestion and air pollution due to private vehicles.

\begin{tabular}{|c|c|c|c|c|c|c|c|c|}
\hline Criteria & $\frac{\sum}{\frac{1}{\Delta}}$ & 式 & $\begin{array}{l}\overrightarrow{0} \\
\circ \\
0 \\
0\end{array}$ & 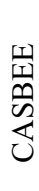 & $\sum_{\substack{\infty \\
\infty}}^{\frac{n}{Z}}$ & 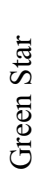 & 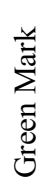 & $\overline{0}$ \\
\hline Management & $\checkmark$ & $\checkmark$ & $\checkmark$ & $\checkmark$ & $\checkmark$ & $\checkmark$ & $\checkmark$ & $\checkmark$ \\
\hline $\begin{array}{l}\text { Sustainable } \\
\text { site }\end{array}$ & $\checkmark$ & $\checkmark$ & $\checkmark$ & $\checkmark$ & $\checkmark$ & $\checkmark$ & & \\
\hline Transport & $\checkmark$ & $\checkmark$ & $\checkmark$ & $\checkmark$ & $\checkmark$ & $\checkmark$ & $\checkmark$ & $\checkmark$ \\
\hline $\begin{array}{l}\text { Indoor } \\
\text { environmental } \\
\text { quality (IEQ) }\end{array}$ & $\checkmark$ & $\checkmark$ & $\checkmark$ & $\checkmark$ & $\checkmark$ & $\checkmark$ & $\checkmark$ & $\checkmark$ \\
\hline Water & $\checkmark$ & $\checkmark$ & $\checkmark$ & $\checkmark$ & $\checkmark$ & $\checkmark$ & $\checkmark$ & $\checkmark$ \\
\hline
\end{tabular}




\begin{tabular}{|l|c|c|c|c|c|c|c|c|}
\hline Waste & $\checkmark$ & $\checkmark$ & $\checkmark$ & $\checkmark$ & $\checkmark$ & $\checkmark$ & $\checkmark$ & $\checkmark$ \\
\hline Material & $\checkmark$ & $\checkmark$ & $\checkmark$ & $\checkmark$ & $\checkmark$ & $\checkmark$ & $\checkmark$ & $\checkmark$ \\
\hline Energy & $\checkmark$ & $\checkmark$ & $\checkmark$ & $\checkmark$ & $\checkmark$ & $\checkmark$ & $\checkmark$ & $\checkmark$ \\
\hline Pollution & $\checkmark$ & $\checkmark$ & $\checkmark$ & $\checkmark$ & $\checkmark$ & $\checkmark$ & $\checkmark$ & $\checkmark$ \\
\hline Innovation & $\checkmark$ & $\checkmark$ & & & $\checkmark$ & $\checkmark$ & $\checkmark$ & $\checkmark$ \\
\hline Economic & $\checkmark$ & & $\checkmark$ & & & & & \\
\hline Social & & $\checkmark$ & $\checkmark$ & $\checkmark$ & $\checkmark$ & & & \\
\hline Cultural & & $\checkmark$ & $\checkmark$ & $\checkmark$ & $\checkmark$ & & & \\
\hline $\begin{array}{l}\text { Quality of } \\
\text { service }\end{array}$ & $\checkmark$ & & $\checkmark$ & $\checkmark$ & $\checkmark$ & $\checkmark$ & & $\checkmark$ \\
\hline
\end{tabular}

Table 1. Comparison of criteria for eight schemes

It is articulated that IEQ criteria has been considered in all of the assessment schemes. Alyami and Rezgui [18] also pointed out that IEQ is one of the popular criteria evaluated in all assessment schemes. It aims to increase health, safety and comfort of building occupants in the building. Poor indoor environments in buildings can pose health risks to building users as they spend most of times inside the building. Water is viewed as limited and valuable resource; hence all of the assessment schemes included it to seek for sustainable water use and management. It is to ensure proper provisions are provided to reduce fresh water consumption in the building. Hence, water recycling such as rainwater harvesting and grey water recycling play an important role in achieving sustainable water management.

Construction activities generated a lot of wastes which require proper management and strategies to recycle or dispose the waste. Hence, waste criterion covered comprehensively in all assessment schemes in ensuring best practice in management of construction and operational waste. It aims to improve waste management and encourage waste recycling and sorting. Building materials are one of the important criterions in the all assessment schemes due to their complicated life cycle process from extracting raw materials till disposal stage [18]. It consumes a large amounts of natural resources, hence material selections is critical to ensure efficient use of materials and avoid wastage.

Assessment schemes place vital importance on energy criterion due to its significant impact on environment. With the increasing concerns about global warming and greenhouse effect, it is necessary to improve energy efficiency of the building by reducing carbon emissions. For pollution, this criterion deals with outdoor sources of air pollution in order to reduce the pollution and adequate provisions are taken to limit the effect of the pollution. Sustainable construction emphasized the protection of the surrounding environment in order to minimise the effect of the construction activities to the surroundings. Majority of the assessment schemes support innovation in the evaluation framework which can provide environmental benefits. Any new methods that can be shown to improve sustainability performance of a building are highly encouraged. In order to encourage exemplary performance in all sustainable aspects, BREEAM and LEED have established supplementary criteria to reflect exceptional performance [18].
In economic aspect, BREEAM and SBTool evaluated the financial aspect whereas the other schemes can be considered relatively weak in this aspect. Raslanas et al. [20] suggested that financial and environmental aspect should go along especially during financial feasibility stage while evaluating alternative development options. In social aspect, LEED, SBTool, CASBEE and BEAM Plus covered the assessment. Social sustainability is essential in taking of care of the welfare (privacy, security, amenities) and equitably distributed among social classes and gender. Culture aspect is neglected in most of the assessment schemes except LEED, CASBEE, SBTool and BEAM Plus. Building development should integrate local cultural value to enhance and promote cultural value in design. Assessment of service functions is crucial to keep the building in good condition in the long term. Therefore, quality of service is one of the important assessment criteria. However, LEED and Green Mark do not evaluate on the quality of service in the assessment scheme.

In summary, SBTool covered most of the assessment criteria not only environmental aspect but also economic, social and cultural aspects which neglected in other assessment scheme. It is affirmed by Raslanas et al. [20] that most of assessment schemes do not cover well in social and economic aspects. However, in order to achieve sustainable development, the economic, social and cultural aspect should not be neglected. Haapio and Viitaniemi [21] stressed out that sustainable building should includes the economic and social aspect in addition to the environmental aspect.

\section{Conclusion and Further Research}

The awareness of the buildings impact on the environment has increased the need for building professionals to consider sustainable design and practice. BIM has the capability to achieve sustainability of design by containing the relevant information in a single coordinated model which allows for various sustainability assessments to be performed at the early stages. However, the application of BIM in sustainability design is relatively low. Hence, this study aims to develop a proof concept of sustainability design by using BIM. The first stage of this study is to carry out a comprehensive review of the existing assessment schemes in order to develop a set of criteria to be used for sustainability design in the second stage.

The assessment schemes chosen for this study are BREEAM, LEED, SBTool, CASBEE, BEAM Plus, Green Star, Green Mark and GBI. The finding of the study showed that there are fourteen common criteria used. There are management, sustainable site, transport, indoor environmental quality, water, waste, material, energy, pollution, innovation, economic, social, culture and quality of services. The less common criteria considered in the assessment schemes are economic, social, culture, and quality of services. It is noted that most of the assessment schemes emphasized more on environmental aspect rather than economic, social and 
culture aspect except SBTool. This is an on-going research. The next stage of the research is to demonstrate the sustainable design through BIM by using the sustainable criteria developed from the initial stage.

\section{Acknowledgement}

This research is supported by British Council NewtonUngku Omar Fund Institutional Links (ID: 172726659) and University of Malaya Institute of Research Management \& Monitoring (IPPP) (grant no: IF0092015).

\section{References}

1. IPCC. Synthesis Report, Intergovernmental Panel of Climate Change. (2007) Available from: https://www.ipcc.ch/pdf/assessmentreport/ar4/syr/ar4_syr_full_report.pdf

2. R. A. Begum, K. Sohag, S. M. S. Abdullah, \& M. Jaafar. $\mathrm{CO}_{2}$ emissions, energy consumption, economic and population growth in Malaysia. Renewable and Sustainable Energy Reviews, 41, 594-601 (2015)

3. NC2. Malaysia's second national communication(NC2) - a report submitted to the United Nations Framework Convention on Climate Change(UNFCCC), Conservation and Environmental Management Division(CEMD),Ministry of Natural Resources and Environment (NRE).Available from: 〈http://nc2.nre.gov. my/〉; 2011[accessed 25 August 2015].

4. Department of Communities and Local Government. Building a greener future: policy statement. (2007)

5. A. Schlueter, and F. Thesseling. Building information model basedenergy/exergy performance assessment in early design stages, Automation in Construction, 18 (2):153-163 (2009)

6. T. Biswas, T. H. Wang, R. Krishnamurti. Integrated sustainable building rating systems with building information modeling. In: Proceedings of the 13th International Conference on Computer Aided Architectural Design Research in Asia, Chiang Mai, Thailand, pp. 193-200 (2008)

7. Autodesk, Inc. Building Information Modeling for Sustainable Design. Autodesk ${ }^{\circledR}$ Revit ${ }^{\circledR}$ White Paper (2005)

8. I. Motawa, and K. Carter. Sustainable BIM-based Evaluation of Buildings, Procedia-Social and Behavioral Sciences, 74:116-125 (2013)

9. S. Azhar, and J. Brown. BIM for sustainability analyses. International Journal of Construction Education and Research, 5(4): 276-292 (2009)

10. S. Azhar, J. Brown, and R. Farooqui, BIM-based sustainability analysis: An evaluation of building performance analysis software. Proceedings of the 45th ASC Annual Conference, Gainesville, Florida (2009)

11. A. Azhar, W. A. Carlton, D, Olsen, and I. Ahmad, Building information modeling for sustainable design and LEED ${ }^{\circledR}$ rating analysis. Automation in construction, 20 (2): 217-224 (2011)

12. R. J. Cole, \& N. Larsson, Building challenge 2002:GBTool user manual (2002) Available from: www.iisbe.org/iisbe/gbc2k5/gbc2k5-start.htm/ [access 20 August 2015].

13. A. Jrade \& F. Jalaei, Integrating building information modelling with sustainability to design building projects at the conceptual stage. In Building Simulation (Vol. 6, No. 4, pp. 429-444). Springer Berlin Heidelberg (2013)

14. E. Krygiel, and B. Nies, Green BIM. Indianapolis: Wiley Publishing, IN (2008)

15. K. C. D. Grace, Sustainable construction-The role of environmental assessment tools. Journal of Environmental Management, 86(3), 451-464 (2008)

16. W. L. Lee, A comprehensive review of metrics of building environmental assessment schemes. Energy and Buildings, 62, 403-413 (2013)

17. CSI (Construction Specifications Institute). The CSI Sustainable Design and Construction Practice Guide. John Wiley \& Sons, Inc (2013)

18. S. H. Alyami, \& Y. Rezgui, Sustainable building assessment tool development approach. Sustainable Cities and Society, 5, 52-62 (2012)

19. BRE. BRE homepage. (2011) Available from: http://www.bre.co.uk/ [access 18 September 2015].

20. S. Raslanas, A. Stasiukynas, \& E. Jurgelaityte, Sustainability assessment studies of recreational buildings. Procedia Engineering, 57, 929-937 (2013)

21. A. Haapio, \& P. Viitaniemi, A critical review of building environmental assessment tools. Environmental impact assessment review, 28(7), 469-482 (2008) 